\title{
The Cells of Human Colostrum. I. In Vitro Studies of Morphology and Functions
}

\author{
C.W.SMITH ${ }^{[29]}$ and A.S. GoldmaN ${ }^{[30]}$ \\ Departments of Pediatrics, Preventive Medicine and Public Health, \\ University of Texas Medical Branch, Galveston, Texas, USA
}

\begin{abstract}
Extract
The morphology and certain functions of human colostral cells were studied in vitro. Colostrum from 60 human females contained neutrophils, small lymphocytes, macrophages and occasional epithelial cells. The median concentration of neutrophils in colostrum from breast-feeding mothers was $150 / \mathrm{mm}^{3}$ as compared to $7000 / \mathrm{mm}^{3}$ in colostrum from those who did not breast feed.

The median concentration of lymphocytes in human colostrum was $205 / \mathrm{mm}^{3}$. Eighty to ninety percent of colostral lymphocytes in culture underwent blastoid transformation after exposure to phytohemagglutinin. Ten to twenty-five percent of cultured lymphocytes were transformed after the addition of specific antigens to the cultures. The synthesis of DNA by blast forms was demonstrated by radioautographic studies with $\mathrm{H}^{3}$-thymidine.

The median concentration of macrophages in colostrum was $2100 / \mathrm{mm}^{3}$. Colostral corpuscles (corpuscles of DonNÉ) were classed with these cells since they displayed identical features. These included glass-adhesive properties, ameboid activity, phagocytosis and presence of abundant lysosomes.

Two types of lymphocyte-macrophage interactions were found in fresh and cultured colostrum. These findings suggested that the interactions occurred in vivo as well as in vitro.
\end{abstract}

\section{Speculation}

These observations indicate that immunologically active cells are normal constituents of human colostrum. The possibility is advanced that these cells may influence the host response of the neonatal recipient.

Introduction

Since BEIGeL's description in 1868 [15] of the cellular nature of the corpuscles of DONNÉ [1], it has been accepted that cells are normal constituents of colostrum. It is now agreed, on the basis primarily of studies in nonhuman animals $[3,14,23,25]$, that lymphocytes, monocytes, macrophages, epithelial cells and colostral corpuscles (corpuscles of DoNNÉ) occur in mammary gland secretions.

The significance of the cells in colostrum is controversial. They have been considered as phagocytes, returning milk substances to the connective tissue of the mammary gland [4], as degenerating cells sloughed during the process of milk secretion [16] or as inflammatory cells appearing in response to infection in the 
mammary gland $[5,20]$. A possible effect of these cells upon the neonatal recipient has not been considered previously.

During an investigation of the proteins of milk, we found cells in human colostrum. On the basis of these observations and because of the relative lack of studies of human colostral cells, we decided to examine the morphology of the cells to determine if they were living and to study their functions.

\section{Methods}

Collection procedure. Colostrum was obtained with a breast pump from 60 women including primigravidas and multigravidas in the first 48 hours following delivery.

Twenty women were nursing their infants and 40 were not. No hormones were given to suppress milk production during the collection period. Women with clinical evidence of mastitis were excluded from this study.

Staining procedures. Dried smears of whole colostrum were stained with tetrachrome [13], methyl greenthionine [19] or sudan black B [7].

Direct observation of cells in whole colostrum with phase contrast microscopy was precluded by the high fat content of colostrum. In order to observe the motility and characteristics of living cells in whole colostrum, therefore, we resorted to supravital staining with acridine orange [8]. A drop of fresh whole colostrum was placed on a coverslip that was inverted onto a microscope slide precoated with acridine orange. This preparation was incubated at $37^{\circ}$ in a high humidity atmosphere for periods of 0.5 to 4 hours. Cells were observed with a Zeiss U.V. light system using a BG 12 exciter filter and a yellow blocking filter.

Cells from cultures were stained with tetrachrome, sudan black B, methyl green-thionine, neutral redJanus green [7] or acridine orange. Some cultured specimens were fixed with $1 \%$ gluteraldehyde in phosphate buffer ( $\mathrm{pH} 7.2$ ), dehydrated and mounted for phase contrast microscopy.

Methods for total cell counts. Because of the high fat content of colostrum, the usual cell counting procedures were difficult and inaccurate. Consequently, alternate methods were devised.

One $\mathrm{ml}$ of colostrum was diluted 1:10 with saline and centrifuged at $400 \times \mathrm{g}$ for 15 minutes. The fat layer and an additional $3 \mathrm{ml}$ of supernatant fluid were removed. The cells obtained by sedimentation were resuspended in the remaining supernatant fluid and counted in a hemocytometer. Cells of diluted colostrum were also counted directly in a hemocytometer after supravital staining with acridine orange [8]. Differen- tial counts were made on smears stained with tetrachrome.

Culture procedures. Colostrum was diluted 1:2 with Hank's solution and centrifuged at $300 \times \mathrm{g}$ for $5 \mathrm{mi}-$ nutes. The sedimented cells were diluted in culture medium to a cell concentration of $1 \times 10^{6}$ mononuclear cells/ml and transferred to Leighton tubes containing coverslips. The final culture medium contained TG 199 and $20 \%$ fetal calf serum (Difco Laboratory, Detroit, Michigan), $300 \mu \mathrm{g} / \mathrm{ml}$ of streptomycin and $300 \mathrm{U} / \mathrm{ml}$ of penicillin-G.

The cultures were treated in several different ways. Phytohemagglutinin (PHA) (Difco Laboratory, Detroit, Michigan) was added to some cultures $(0.005 \mathrm{ml}$ PHA/culture) at the onset and incubation was continued for 72 hours. When specific antigens (penicillin$\mathrm{G}$, tetanus toxoid, diphtheria toxoid or PPD) were added, incubation was continued for five days. In other cultures, no stimulants were added. The cells adhering to the coverslip were fixed by immersing in $1 \%$ gluteraldehyde after $3,24,48$ or 72 hours of incubation.

Blastoid transformation of the lymphocyte was evaluated on the basis of the characteristic morphology of the blast forms. The relative frequency of transformation was determined on counts of 1000 lymphocytes/ culture sample.

Radioautography. The synthesis of deoxyribonucleic acid (DNA) was examined in these various types of cultures by radioautography. One $\mu \mathrm{c}$ of tritiated thymidine was added to each $\mathrm{ml}$ of culture medium one hour before completing the incubation period. The cells were collected by centrifugation, smeared on glass slides and coated with $\mathrm{NTB}_{3}$ liquid emulsion (Eastman Kodak Company, Rochester, New York). The slides were exposed for a period of four to seven days, then developed [24] and stained with tetrachrome.

Phagocytosis. In order to determine the phagocytic activity of colostral cells, heat-killed staphylococci were added to the culture to produce a final concentration of $1 \times 10^{8}$ organisms $/ \mathrm{ml}$ of culture medium. The culture tubes were then gently agitated for 15,30 or 60 minutes at $37^{\circ}$ in a water bath. The coverslips were removed, washed with saline and stained with tetrachrome.

\section{Results}

Morphology of colostral cells. Morphologically, the neutrophils were typical of those seen in the blood except that they contained numerous fat globules and fewer granules (fig. 1A). Small lymphocytes (fig. 1B) and monocytes were similar to those from blood except that fat vacuoles were occasionally found in their cytoplasm. Epithelial cells usually contained a single large vacuole and an eccentric nucleus, somewhat like a signet ring. 
No plasma cells, erythrocytes or other types of cells were seen.

Macrophages (fig. 1C) were mononuclear cells with abundant cytoplasm containing many fat globules and other granular material. The nucleolus was prominent and the cytoplasm occasionally had areas that stained metachromatically with thionine. The typical colostral corpuscle (fig. 1D) was a large mononuclear cell, some-

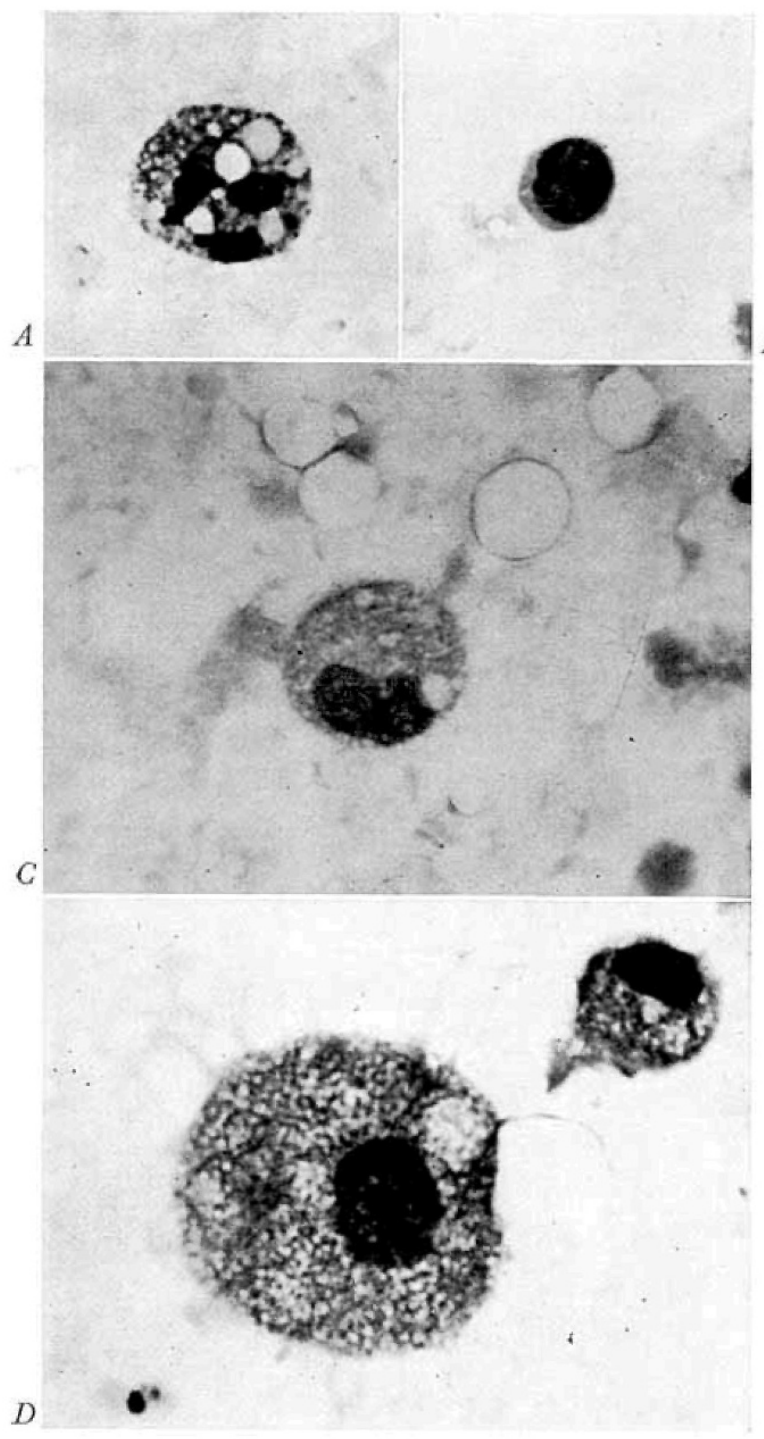

Fig.1. Photomicrograph of cells of fresh human colostrum $(1000 \times$ magnification).

$A$. A neutrophil containing fat vacuoles; $B$. A small lymphocyte; $C$. A macrophage containing fat vacuoles and granular material in the cytoplasm; $D$. A typical colostral corpuscle (corpuscle of DonNÉ). times as large as $30 \mu$ in diameter. The nucleolus was prominent and the cytoplasm appeared engorged with fat. No clear distinction could be made between macrophages and colostral corpuscles, since all gradations of intermediate types were present.

Concentration of colostral cells. For the purpose of tabulating cell frequencies, colostral corpuscles were considered as macrophages. The median concentration of macrophages was 2100 cells $/ \mathrm{mm}^{3}$ (range $500-3000$ ). The median concentration of lymphocytes was 205 cells/ $\mathrm{mm}^{3}$ (range 80-255). Typical monocytes were very rare. The counts from breast-feeding and nonbreast-feeding women were very similar.

The concentration of neutrophils was quite variable. In colostrum from 12 nonbreast-feeding women, the median count was $7000 / \mathrm{mm}^{3}$ (range $800-9000$ ) whereas from 8 breast-feeding women the median count was $B 150 / \mathrm{mm}^{3}$ (range 0-300).

Supravital staining with acridine orange. The nuclei and nucleoli of the cells displayed bright green fluorescence. The cytoplasm of macrophages and colostral corpuscles stained both metachromatically (red fluorescence) and orthochromatically (green fluorescence).

The metachromasia appeared in numerous granules while the green fluorescence of the cytoplasm tended to be more homogeneous. Some portions of the cytoplasm, such as the cytoplasmic veil, did not stain. After incubation of from two to four hours, many of the macrophages and colostral corpuscles exhibited ameboid movement, some extending long pseudopodia. Most of these cells showed evidence of spreading on the glass surface.

Lymphocyte stimulation. Eighty to ninety percent of colostral lymphocytes cultured in suspension with PHA underwent blastoid transformation, whereas less than $1 \%$ were transformed in control cultures. There was evidence of DNA synthesis in $12 \%$ of the lymphocytes from $\mathrm{PHA}$-treated cultures (fig. 2). The relative frequency of blastoid transformation of colostral lymphocytes exposed to specific antigens is shown in table I.

Macrophages. Cultures without mitogens or specific antigens were used to evaluate some of the properties of the colostral macrophages. Collection of these cells from cultures was facilitated by their propensity to adhere to coverglasses. Morphologically, they were mononuclear with a prominent nucleolus and abundant irregular cytoplasm. Some had markedly vacuolated cytoplasm and appeared to be colostral corpuscles (fig. 3). Most were typical macrophages containing only a few cytoplasmic vacuoles (fig.4). Other cell types were monocytes or spindle-shaped cells resem- 
Table I. Response of colostral lymphocytes in culture to PHA or specific antigens

\begin{tabular}{llll}
\hline $\begin{array}{l}\text { PHA or } \\
\text { antigen }\end{array}$ & $\begin{array}{l}\text { Number } \\
\text { of patients }\end{array}$ & $\begin{array}{l}\text { Number } \\
\text { of cultures }\end{array}$ & $\begin{array}{l}\text { Blastoid } \\
\text { transformation } \\
\%\end{array}$ \\
\hline None & 20 & 20 & 2 \\
PHA & 30 & 30 & $80-90$ \\
Tetanus & $2^{1}$ & 3 & 12 \\
$\quad$ toxoid & & & \\
Penicillin & $1^{2}$ & 3 & 25 \\
Diphtheria & $1^{1}$ & 3 & 18 \\
PPD & $1^{3}$ & 3 & 10 \\
\hline
\end{tabular}

1 Individuals immunized 3 weeks prior to delivery. Control cultures yielded less than $1 \%$ blastoid transformation.

${ }^{2}$ Individual with past history to penicillin allergy. Control cultures yielded less than $2 \%$ blastoid transformation.

${ }^{3}$ Individual with positive tuberculin skin test.

bling fibroblasts. These fibroblast-like cells were found after three to six days of incubation and never totaled more than $0.1 \%$ of the cells on the coverslip.

Macrophages contained abundant neutral red positive granules and granules staining metachromatically with acridine orange. Some areas of their cytoplasm also stained metachromatically with thionine. Sudan black B staining demonstrated abundant fat in the cytoplasm of most of the cells on the coverslip; colostral corpuscles were most heavily stained. After three to six days of incubation, a decrease in the fat staining occurred and the cells appeared more homogeneous.

In contrast to the typical macrophages, the fibroblast-like cells contained few neutral red or acridine orange positive granules; their cytoplasm stained metachromatically with thionine and toluidine blue and showed little evidence of cytoplasmic fat.

Most of the macrophages migrated in an ameboid manner or spread on the glass surface and extended a cytoplasmic veil (ectoplasm). Even cells engorged with fat were ameboid (fig.5). Phagocytic functions of colostral macrophages were demonstrated. After adding staphylococci to the cultures, 10,60 and 75 percent of the cells on the coverslips contained bacteria at the respective intervals of 15, 30 and 60 minutes. Many of the cells containing bacteria were colostral corpuscles. Also attesting to the phagocytic capability of these cells was the frequent observance of phagosomes containing degenerating neutrophils (fig.4).

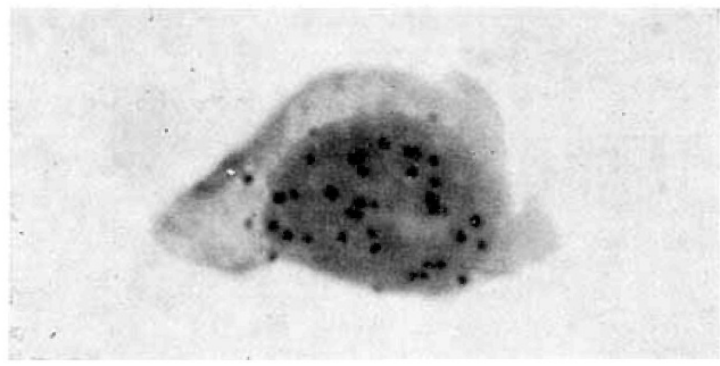

Fig. 2. Radioautograph of a lymphoblast from a culture of colostral lymphocytes stimulated with PHA $(1000 \times$ magnification). Numerous silver grains over the nucleus denote specific nuclear incorporation of $\mathrm{H}^{3}$-thymidine and indicates DNA synthesis.

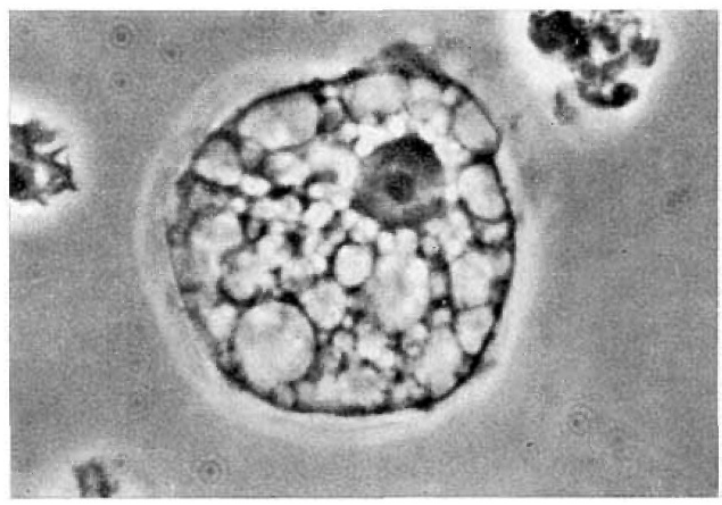

Fig.3. Photomicrograph of a colostral corpuscle (corpuscle of DONNÉ) in culture $(1000 \times$ magnification $)$.

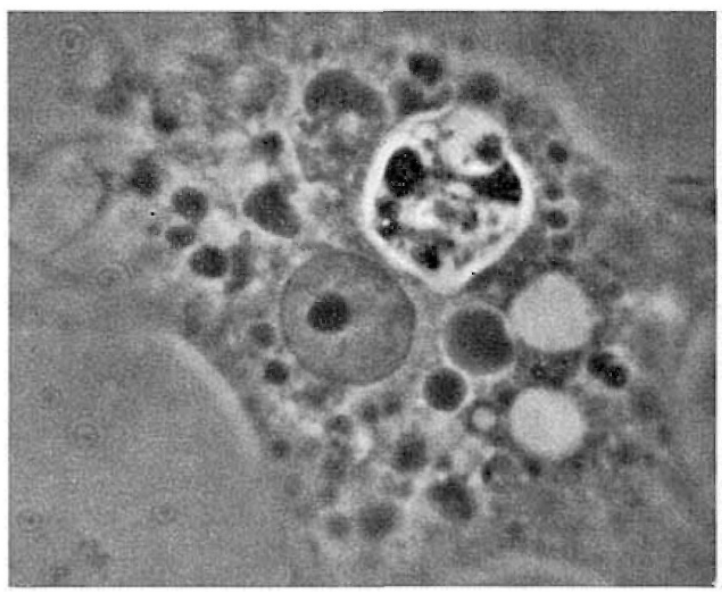

Fig.4. Photomicrograph of a colostral macrophage in culture $(1000 \times$ magnification). A few large vacuoles and a phagocytized neutrophil are seen. 


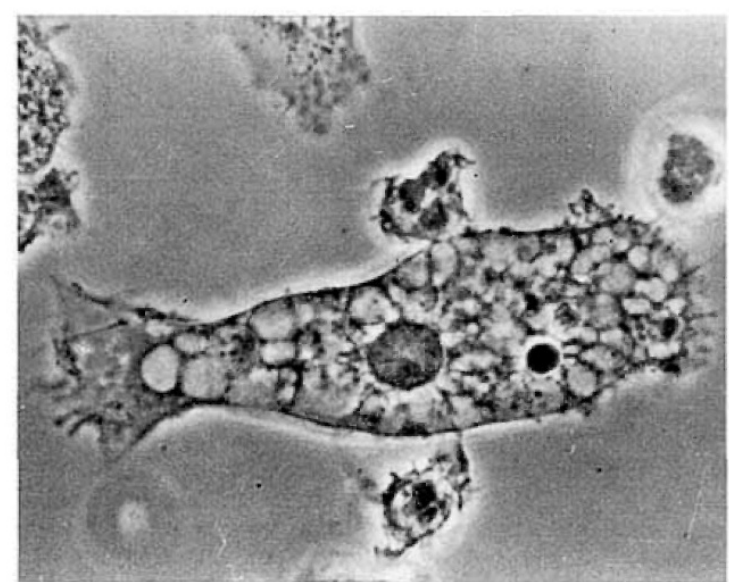

Fig.5. Photomicrograph of a colostral corpuscle (corpuscle of DoNNÉ) in culture showing ameboid activity $(1000 \times$ magnification $)$.

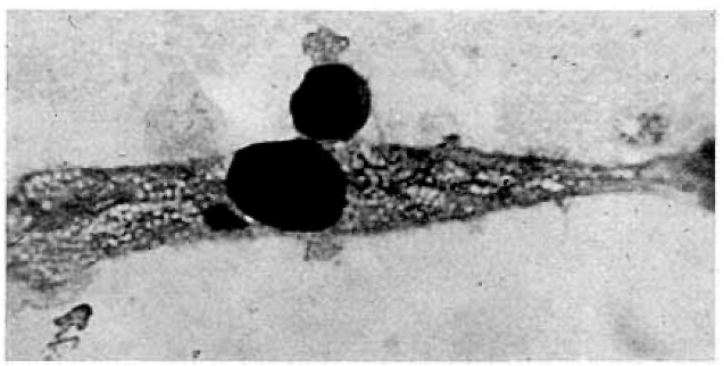

Fig.6. Photomicrograph of lymphocyte-macrophage interaction in colostral cell culture $(1000 \times$ magnification). The lymphocyte is situated away from the migrating portion of the macrophage.

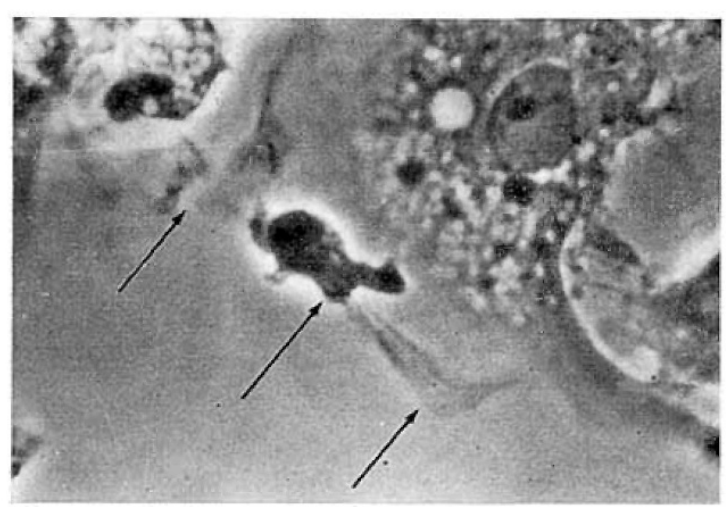

Fig.7. Photomicrograph of lymphocyte-macrophage interaction ( $1000 \times$ magnification). The lymphocyte is situated on the ectoplasm of the macrophage (see arrows) and extends a single cytoplasmic process to the granular portion of the cytoplasm of the macrophage.
Lymphocyte-macrophage interactions. Lymphocyte-macrophage interactions were observed frequently in whole fresh and cultured preparations of colostrum. In fresh colostrum stained supravitally with acridine orange, it was demonstrated that the lymphocytes were in contact with colostral cospuscles as well as other macrophages. The cytoplasm of the associated lymphocyte usually contained one to four metachromatic granules. Occasionally a single cytoplasmic process of the Iymphocyte extended to the macrophage.

Lymphocyte-macrophage interactions were found in all cultures. One to five percent of the macrophages on the coverslips had an associated lymphocyte. Two types of interaction were evident. When the lymphocyte was in contact with a macrophage that appeared to be migrating, the lymphocyte was round with no discernible cytoplasmic processes; when the process was present, it was generally situated near the tail of the migrating macrophage (fig.6). When the lymphocyte was associated with a macrophage that was spread on the glass and appeared stationary, the lymphocyte characteristically had a single cytoplasmic process extending to the cytoplasm of the macrophage (fig. 7). The nucleus of the lymphocyte was usually over the ectoplasm of the macrophage with its pseudopod extending toward the granular portion of the cytoplasm of the macrophage. Since cinemicrography was not performed, it is unknown whether this anatomic relation was stationary or whether the lymphocyte migrated about the macrophage ('peripolesis').

\section{Discussion}

The types of cells in human colostrum are essentially the same as those found in colostrum of other species $(3,14,23,25]$. The regularity of occurrence of these cells suggests the presence of a highly ordered cytologic system of functional importance.

Investigations of cells in colostrum have concentrated largely on the neutrophil, since its presence has been considered to indicate infection of the mammary gland $[5,20]$. Neutrophils were abundant in colostrum from nonnursing mothers and rare in colostrum from nursing mothers, indicating that they probably appear in response to engorgement of the breast. The presence of neutrophils in human colostrum can no longer be accepted solely as evidence of infection of the mammary gland.

With the exception of the colostral corpuscles, the identity of other cells in mammalian colostrums has been well understood. Our studies indicate that human colostral corpuscles are macrophages engorged with fat. In smears of fresh colostrum stained with tetrachrome, all gradations of morphologic types between 
typical macrophages and colostral corpuscles were found. In fresh colostrum, these cells were motile, phagocytic and contained abundant lysosomes as indicated by numerous neutral red and acridine orange positive granules [10]. In cultures, these cells again displayed phagocy tosis and glass-adhesive and ameboid activity typical of macrophages [9].

The response of human colostral lymphocytes to PHA and specific antigens by blastoid transformation and DNA synthesis appears qualitatively and quantitatively similar to that of lymphocytes from peripheral blood $[6,18]$. Many studies indicate that this type of transformation following exposure to antigens indicates specific immunologic reactivity of the cells $[2,17$, 18]. Our findings strongly suggest that immunologically active lymphocytes are normal constituents of human colostrum.

Lymphocyte-macrophage interaction, an event of presumed immunologic significance $[11,22]$, was observed in fresh colostrum and in all colostral cell cultures. In cultures of cells from lymph nodes [22], spleen [22], thymus [21] and blood [12], these cellular interactions have been observed but in these instances, it was impossible to conclude that this phenomenon occurred in vivo [11]. The present investigation of cells of fresh human colostrum provided a unique opportunity to observe lymphocyte-macrophage interactions in a natural body fluid with a minimum of manipulation and in vitro incubation. The observation of lymphocytemacrophage interactions under these conditions argues that this is a phenomenon that occurs naturally in vivo.

The breast-fed newborn infant normally receives colostral cells. It is possible that these maternal cells may influence the immunologic status of the recipient neonate. Further investigations will be necessary to identify what role these cells play in the human infant; however, additional in vitro studies of the immunologic activities of these cells are needed before it will be possible to undertake experiments designed todemonstrate an in vivo effect.

\section{References and Notes}

1. Donné, A.: Cours de microscopie, vol. 1 et Atlas No. 1 (Baillière, Paris 1844-1845).

2. Elves, M.W.; Roath, S. and Israels, M.C.G.: The response of lymphocytes to antigen challenge in vitro. Lancet $i: 806$ (1963).

3. Emmel, V.E.; Weatherford, H.L. and StreiCHER, M.H.: Leucocytes and lactation. Amer.J. Anat. 38: 1 (1926).

4. Gruber, G. B.: Beiträge zur Histologie und Pathologie der Mamma. Virchows Arch.path. Anat. Cit. by MAyer, G. and Klein, M. 248: 397 (1924).
5. Hadwen, S.: Microscopic detection of mastitis. Amer.J.vet. Res. 1: 11 (1940).

6. HirschHorn, K.; Bach, F.; Kolodny, R.L.; Firschein, J. L. and Hashem, N.: Immune response and mitosis of human peripheral blood lymphocytes in vitro. Science 142: 1185 (1963).

7. Humason, G. L. : Animal tissue techniques, $2 \mathrm{nd}$ ed. (Freeman, San Francisco 1967).

8. JAckson, J. F.: Supravital blood studies using acridine orange fluorescence. Blood 17: 643 (1961).

9. JАсову, F.: Macrophages; in Cells and tissues in culture. Methods, biology and physiology, vol. 2 (ed. Willmer, E. N.) (Academic Press, New York 1965).

10. Koenig, H. : Vital staining of lysosomes by acridine orange (Abstr.). J. Cell Biol. 19: 87A (1963).

11. MacFarland, W. and Heilman, D. H.: Lymphocyte foot appendage: Its role in lymphocyte function and in immunological reactions. Nature, Lond. 205: 887 (1965).

12. MacFarland, W.; Heilman, D.H. and MoorHEAD, J.F.: Functional anatomy of the lymphocyte in immunological reactions in vitro.J. exp. Med. 124: 851 (1966).

13. MAcNeAL, W.J.: Tetrachrome blood stain: An economical and satisfactory imitation of Leishman's stain. J.amer. med. Ass. 78: 1122 (1922).

14. Maximov, A.A. and Bloom, W.: A textbook of histology, 5th ed. (Saunders, Philadelphia, 1948).

15. MAYer, G. and Klein, M.: Histology and cytology of the mammary gland; in Milk: The mammary gland and its secretions (ed. Kon, S. K. and CRowie, A.T.), p. 363 (Academic Press, New York 1961).

16. Okada, M.: Histology of the mammary gland. VII. Histological and histochemical studies of cells in the milk of domestic animals. Tôhoku J.Agr. Res. 11: 31 (1960).

17. Pearmain, G.; Lycette, R.R. and Fitzgerald, P.H.: Tuberculin induced mitosis in peripheral blood leucocytes. Lancet $i$ : 637 (1963).

18. Roвbins, J.H. : Tissue culture studies of the human lymphocyte. Science 146: 1648 (1964).

19. Rogue, A.L.; Jafarey, N.A. and Coulter, P.: A stain for the histochemical demonstration of nucleic acids. Exp.molecul. Path. 4: 266 (1965).

20. Schalm, O.W.; Lasmanis, J. and Carroll, E. I.: Pathogenesis of experimental coliform (Aerobacter aerogenes) mastitis in cattle. Amer.J.vet. Res. 25: 75 (1964).

21. Sharp, J.A.: Adhesion of lymphocyte to large motile cells in culture of rabbit thymus. Nature, Lond. 209: 828 (1966).

22. Sharp, J.A. and Burwell, R.G.: Interaction ('peripolesis') of macrophages and lymphocytes after skin grafting or challenge with soluble antigens. Nature, Lond. 205: 887 (1965). 
23. VARRIER-Jones, P. G. : The cellular content of milk: Variations met with physiological and pathological conditions. Lancet $i i: 537$ (1924).

24. Walker, B.E.: Personal communication (1963).

25. ZlotnIK, I.: Types of cells present in cows' milk. J.comp.path. 57: 196 (1947).

26. The authors wish to express their appreciation to Mr. James G. Hollers for his technical assistance and to L.C. Powell, M.D., of the Department of Obstetrics and Gynecology, without whom this study would not have been possible.
27. Presented in part at the Society for Pediatric Research. Atlantic City, New Jersey, April 29, 1967. 28. Supported in part by NIH Grants ROI HD 0073503 and NIH-1-SO1-FR 05427-06 and the Shriners Burns Institute, Galveston, Texas.

29. Clifton W.Smith is a James W.MaLaughlin Pre-doctoral Fellow.

30. Requests for reprints should be addressed to: Dr. Armond S. Goldman, Associate Professor of Pediatrics, The University of Texas Medical Branch, Galveston, Tex. 77550 (USA). 